\title{
Latin American scientific output in Public Health: combined analysis using bibliometric, socioeconomic and health indicators
}

\author{
Zaida Chinchilla-Rodríguez • Grisel Zacca-González • \\ Benjamín Vargas-Quesada · Félix Moya-Anegón
}

Received: 25 February 2014/Published online: 24 June 2014

(C) Akadémiai Kiadó, Budapest, Hungary 2014

\begin{abstract}
This study characterizes the volume and visibility of Latin American scientific output in the area of Public Health, through a combined analysis of bibliometric, socioeconomic and health indicators of the top 10 Latin American producers of documents. The information was obtained from the SCImago Institutions Rankings (SIR) portal, based on Scopus data, in the category Public Health, Environmental and Occupational Health, of the area Medicine, for the period 2003-2011. Our scientometric analysis involved a set of quantitative indicators (based on document recount), plus performance ones to measure impact and excellence (based on citation recount) and international collaboration. The socioeconomic indicators measured investment in health and in research, and the number of researchers. Basic health indicators were used, along with the inequity indicator known as INIQUIS. The main results reveal that the research systems with the greatest capacity to communicate scientific results are those of Brazil and Mexico, and potentially Colombia and Argentina. The best visibility was demonstrated by Uruguay, Puerto Rico and Peru, countries with high rates of collaboration. No single country stands out as having a perfectly balanced relationship regarding all the dimensions analyzed. A relative balance is achieved by Brazil, Uruguay and Argentina, though with different levels of scientific output. The tangible achievements in health attained by Cuba and Chile do not appear to be related with the results of research published in the area of Public Health. There is clearly a need to find methods that would allow us to evaluate the transfer of research knowledge into practice, by means of the scientometric perspective.
\end{abstract}

Z. Chinchilla-Rodríguez

CSIC, Institute of Public Goods and Policies, Madrid, Spain

G. Zacca-González

Department of Teaching and Research, National Medical Sciences Information Centre Infomed, Havana, Cuba

B. Vargas-Quesada $(\bowtie)$

Department of Information \& Communication, University of Granada, Granada, Spain e-mail: benjamin@ugr.es

F. Moya-Anegón

CSIC, Institute of Public Goods and Policies, Madrid, Spain 
Keywords Public Health - Latin America - Research evaluation - Bibliometrics · Health indicators $\cdot$ Socioeconomic indicators

\section{Introduction}

The World Health Organization (WHO) acknowledges the importance of investigation in the search for solutions to health problems worldwide, and to improve the state of health of populations. Research is essential to clarify the nature and scope of health problems, as well as to define effective interventions and strategies (Organización Panamericana de la Salud 2008). Apparently, however, not all Latin American countries uphold Health-related research as a crucial element for human and economic development, for which reason it is not always given the priority necessary to fuel its advancement COHRED (2006).

The first Latin American Conference on Research and Innovation for Health, celebrated in Brazil in April of 2008, sought practical responses in the face of challenges common to the whole region, to funnel research toward health priorities and contribute to the equitable development of the region. To this end, it emphasized the creation, development and fortification of national health research systems, and regional cooperation, as means of taking best advantage of the existing resources and reduces inequalities. Alger et al. (2009).

In the past decade, some Latin American countries have made consistent and substantial investments in health research. They have prioritized topics considered relevant to improve health and further the development of a health system in each country. Notwithstanding, the scarcity of funds continues to be a major problem affecting the countries of this region. Financing is not only difficult to obtain; it is either not sustained or altogether inexistent (COHRED 2006; Maloney 2009). Moreover, the economic growth of the region is not reflected by a greater funding for research and development $(\mathrm{R}+\mathrm{D})$ in a homogenous fashion, across boundaries. UNESCO's Report on Science 2010 shows the gross domestic product (GDP) of the region to have increased substantially between 2002 and 2007-from 3741.2 to 5640.7 billion dollars. This means a proportional rise in world participation, from 8.0 to $8.5 \%$. This growth in the GDP is reflected in the Gross Domestic Expenditure on R\&D (GERD), with an increase from 22.1 to 34.6 million dollars of PPA (from 2.8 to $3.0 \%$ of the world Gross Expenditure for Research and Development) between 2002 and 2007. The ratio between GDE-RD and percentage of GDP remained stable, at $0.6 \%$.

The deficit in human resources is another factor influencing the results of scientific research. The number of researchers expressed as the equivalent of a full work day, at the regional level, increased from 169.9 to 252.1 thousands of researchers between 2002 and 2007, respective proportions of the worldwide distribution of researchers of 2.9 and $3.5 \%$. As far as Public Health is concerned, there is a critical mass of researchers that has made a considerable scientific contribution to the world literature despite the limitation of resources. Although Latin America has a strong tradition of Public Health schools and academic centers, with at least 34 universities and institutions offering Masters and Ph.D. programs in Epidemiology and Public Health (Barreto et al. 2012), there are evident problems in training and retaining researchers (Magaña-Valladares et al. 2009). Public Health Schools do not have sufficient tutors to attract doctoral students Mays et al. (2003), and the problem known as "brain drain" comes as a consequence of the inability to keep researchers on national soil (Maloney 2009).

Within Latin America, the countries with systems of research that are integrated are Argentina, Brazil, Chile, Costa Rica and Mexico, whereas the countries with semi-structured systems are Colombia, Panama and Venezuela. The countries with a system under 
development or in a stage of reinforcement are Bolivia, Honduras, Paraguay and Uruguay Becerra-Posada (2009).

Advances in the national research systems for Health in Latin America, as reported by the Council of Research in Health for Development (COHRED) include: in Argentina the priorities in health research were defined, and the Minister of Science and Technology was created; Brazil increased the fraction of public funding dedicated to research; Colombia is in the process of implementing agendas of priorities; Cuba increased financing to create capacities for research; Mexico increased public funding for research as well as the number of positions destined for research; and Uruguay created funds for research in health coordinated by their Health Ministry and National Agency of Research and Innovation. It is now necessary to evaluate different aspects affected by the reforms in these countries, from financing to the results of scientific activities. According to Gilson, successful implementation of reforms requires attention to policy and strong political and technical skills to effectively manage processes of change (Gilson 1999). A successful analysis of the literature demands the establishment of a diagnosis of the existing situation in order to identify relevant indicators of literature production and visibility (Macías-Chapula 2005a, b). Up to date, no clear picture or systematic study exits as to the results or impact of this support by international and national agencies. Some results at the regional level make manifest three fundamental shortcomings that partly motivated our study: the lack of national plans for research into Public Health, the lack of periodical evaluation in fulfilling the program, and the absence of formal and transparent mechanisms for the assignment of research resources in many countries (Pan American Health Organization 2002, 2007).

On the other hand, developing the capacity to effectively carry out essential health research is an integral part of health research systems at both the national and global levels. Research capacity is the ability to define and prioritize problems systematically, develop and scientifically evaluate appropriate solutions and share and apply the knowledge generated (Lansang and Dennis 2004). To assess research capacity social, economic, political components should be considered. Some of them are infrastructures and resources, policy and government commitment, financing, the number and distribution of schools of Public Health, Public Health teaching programs, Public Health researchers and post-graduate students, research facilities, information (library facilities and online access), research culture, publication, leaderships, partnerships, collaborations and research networking integration, knowledge translation and exchange mechanisms, etc....

In this context, a previous study undertook an external, systematic and objective evaluation of the scientific output of Latin America as a macro aggregate and its comparison worldwide (Zacca-González et al. 2014) as a basic analytical instrument to establish points of reference and facilitate decision-making regarding research policies related with health. In the present study, the focus is on the main countries producing knowledge in Public Health research.

\section{Objective}

The aim of this study is to analyze the main results of scientific output with international visibility from the principal producers of knowledge in the region of Latin America, together with socioeconomic and health indicators. The research questions we planted were: What is the research capacity of these systems to communicate research results through international channels within the specific domain of Public Health? How much 
have they produced, how visible are they and what are the main patterns of publication taking into account the socioeconomic and health context?

\section{Materials and methods}

The bibliometric information was extracted from the SCImago Institutions Rankings portal SCImago (2007), based on Scopus data (2013) (Moya-Anegón et al. 2007), for the category Public Health, Environmental and Occupational Health of the area Medicine, in the period 2003-2011. Aside from the geographic consideration, the selection of Latin American countries entailed two criteria of inclusion-that the country produced at least 1,000 documents in the subject area Medicine, and 100 in the category Public Health, during the period 2003-2011. Ten countries fulfilled these pre-requisites: Brazil, Mexico, Colombia, Cuba, Chile, Argentina, Peru, Venezuela, Puerto Rico and Uruguay. All types of documents are considered, including citable and non citable documents indexed in journals covered by Scopus. Although it has been demonstrated that gray literature documents such as books, websites, technical reports, surveys, thesis and official norms are important channels of scientific communication in Public Health (Macías-Chapula 2010), the exclusion of this type of documents is a limitation of this paper.

To obtain data about the worldwide population and investment indicators, we used the portal of the World Bank (2010) and that of UNESCO's Institute of Statistics (UIS). The health indicators were adopted from the Global Health Observatory of the World Health Organization (Global Health Observatory, 2013).

Table 1 offers a description of the bibliometric, socioeconomic and health indicators used.

\section{Results}

During the period 2003-2011 Scopus recorded 211,601 documents in Public Health worldwide. Latin America put out 13,912 of these documents (6.57\% of world output). The 10 Latin American countries with greater output produced, altogether, over $90 \%$ of all the regional literature in Public Health registered in Scopus during the 9-year period of study (Table 2).

Countries can be grouped according to the volume of scientific output in four levels, been Brazil the high producer; Mexico, Colombia, Cuba, Chile and Argentina medium; Peru, Venezuela, Puerto Rico and Uruguay low; and the rest of the Latin American countries that were not included in this paper and had less of 100 in the category Public Health, during the period 2003-2011 could be considered very low producers.

Brazil provided $67.3 \%$ of the total documents of the region, and Mexico $14.7 \%$. That is, just two countries are responsible for over $80 \%$ of Latin American output. The growth rate of Brazil was the highest (278\%) registered for any country in the region, and derives largely from the 5-year period of 2003-2007; meanwhile, the volume of Mexican production decreased in the 2007-2011 by $6.5 \%$. After an important gap in the regional output values, we find Colombia and Chile in third and fourth places, respectively with 6 and $5.4 \%$ of publications. These two countries grew below the regional rate of growth for the period overall (291\%), advancing more between 2003 and 2007 than in subsequent years. Cuba occupies the fifth position, with nearly $5 \%$ of Latin America's output; its rate of growth is $223 \%$, below the regional mean and slowing down in more recent years. 
Table 1 Listing of bibliometric, health and socioeconomic indicators

Indicator Description

\section{Bibliometric indicators}

Number of documents (Ndoc)

Percentage of documents $(\% \mathrm{Ndoc})$

Rate of growth (RG)

Number of documents per one million inhabitants

Citations per document (Cpd)

Normalized impact (NI)

Publications of high quality (\% Q1)

Scientific excellence (\% Exc)

Scientific leadership (\% Lead)

Excellence with leadership (\% EwL)

International collaboration $(\% \mathrm{Col})$
Total number of documents published by each country

Percentage of documents with respect to the aggregate of reference. To compare output among countries, the reference value taken was the total number of documents produced by Latin American countries

Percentage-wise difference in the number of papers published with respect to the previous period

Average number of documents per one million inhabitants per year

Average citations received for total scientific production of a country during the period of study

Relative number of citations received by each country, compared with the world mean for citations per document of the same type, year and category. It is calculated using the methodology "Item oriented field normalized citation score average" established by the KarolinskaIntitutet of Sweden, by which citation values are normalized at the level of the individual article Rehn and Kronman (2008). The values (\%) show the relationship between the mean scientific impact of a country and the worldwide average on the whole, with a score of 1 . Therefore, an NI of 0.8 means that the country is cited $20 \%$ less than the world average; a score of 1.3 means it is cited $30 \%$ more than the world average

Percentage of publications in journals included in the first quartile (top $25 \%$ ) of the category Public Health, according to SJR (González-Pereira et al. 2010)

Percentage of scientific output of a country that was included in the group of $10 \%$ of most cited works in Public Health. Hence, this measures the amount of high quality scientific output (Bornmann et al. 2012)

Percentage of output of a country in which the main author ("corresponding author") belongs to the national institutions of a given country. These are known as leadership documents (MoyaAnegón et al. 2013)

Percentage of leadership documents of a country that are also among the $10 \%$ most cited ones (Jeremić et al. 2013)

Percentage of output of a country published in collaboration with other institutions outside the country

\section{Indicators of investment and researchers}

Total expenditure in health

Sum of public and private spending on health. It is expressed as percentage of the gross domestic product (\% of GDP) and as US\$ at current prices. The rate of growth was calculated as the percentagewise difference between years of the study period

Current and capital expenditure (public and private) in the creative work carried out systematically to increase knowledge and use it for new applications. It takes in basic and applied research, as well as experimental developments

Researchers

Professionals dedicated to the design or creation of new knowledge, products, processes, methods or systems, and to the management of the corresponding projects. It is expressed as a number per one million inhabitants 
Table 1 continued

\begin{tabular}{|c|c|}
\hline Indicator & Description \\
\hline $\begin{array}{l}\text { Researchers (medical and health } \\
\text { sciences) }\end{array}$ & $\begin{array}{l}\text { Professionals of the medical and health sciences who are dedicated to } \\
\text { research, or those who do research collaterally, in addition to their } \\
\text { main activity }\end{array}$ \\
\hline \multicolumn{2}{|l|}{ Health indicators } \\
\hline Life expectancy at Barth & $\begin{array}{l}\text { Number of years that a newborn would live according to the patterns } \\
\text { of mortality, if these do not change throughout the lifetime of the } \\
\text { infant }\end{array}$ \\
\hline Infant mortality & $\begin{array}{l}\text { Number of children who do not survive the first year of life, per each } \\
1,000 \text { live births }\end{array}$ \\
\hline Mortality, children under age 5 & $\begin{array}{l}\text { Probability that a child would die before reaching the age of five, per } \\
1,000 \text { live births }\end{array}$ \\
\hline Maternal mortality & $\begin{array}{l}\text { Number of women who die during pregnancy and childbirth, per } \\
100,000 \text { live births }\end{array}$ \\
\hline $\begin{array}{l}\text { Index of health inequities } \\
\text { (INIQUIS) }\end{array}$ & $\begin{array}{l}\text { This index, adopted from Cardona, Acosta and Bertone, accounts for } \\
\text { numerous indicators of health and the socioeconomic context, } \\
\text { summing up the health situation of a given country. It assesses the } \\
\text { state of inequalities in health in a simple manner, adopting values } \\
\text { between } 0 \text { and } 1 \text { (scores near } 0 \text { corresponding to a better health } \\
\text { context) }\end{array}$ \\
\hline
\end{tabular}

Table 2 Rate of growth and relative contribution to regional scientific output in Public Health of the main Latin American producers

\begin{tabular}{|c|c|c|c|c|c|}
\hline \multirow[t]{2}{*}{ Country } & \multirow[t]{2}{*}{ Ndoc } & \multirow[t]{2}{*}{$\%$ Ndoc } & \multicolumn{3}{|c|}{ Rate of growth } \\
\hline & & & 2003-2011 & 2003-2007 & 2007-2011 \\
\hline Brazil & 9,356 & 67.25 & 278.57 & 150.67 & 51.02 \\
\hline Mexico & 2,046 & 14.71 & 82.17 & 94.90 & -6.54 \\
\hline Colombia & 839 & 6.03 & 270.27 & 113.51 & 73.42 \\
\hline Chile & 747 & 5.37 & 172.73 & 125.00 & 21.21 \\
\hline Cuba & 693 & 4.98 & 223.81 & 126.19 & 43.16 \\
\hline Argentina & 627 & 4.51 & 285.29 & 70.59 & 125.86 \\
\hline Peru & 315 & 2.26 & 233.33 & 61.11 & 106.90 \\
\hline Venezuela & 204 & 1.47 & 31.58 & 47.37 & -10.71 \\
\hline Puerto Rico & 202 & 1.45 & 125.00 & 125.00 & 0.00 \\
\hline Uruguay & 107 & 0.77 & 44.44 & 0.00 & 44.44 \\
\hline Latin America & 13,912 & 100 & 291.24 & 188.37 & 44.94 \\
\hline
\end{tabular}

Scopus 2003-2011

Source SCImago Institutions Rankings, from Scopus data elaborated by the authors

Argentina shows an output figure similar to Cuba's, yet its volume of documents underwent noteworthy growth from 2007 to 2011. Peru, Venezuela and Puerto Rico each produced between 2.5 and $1.5 \%$ of the regional total, while the share of the remaining countries is around $1 \%$ or less. Venezuela and Mexico present decreasing values for output in the final period (Table 2; Fig. 1). 


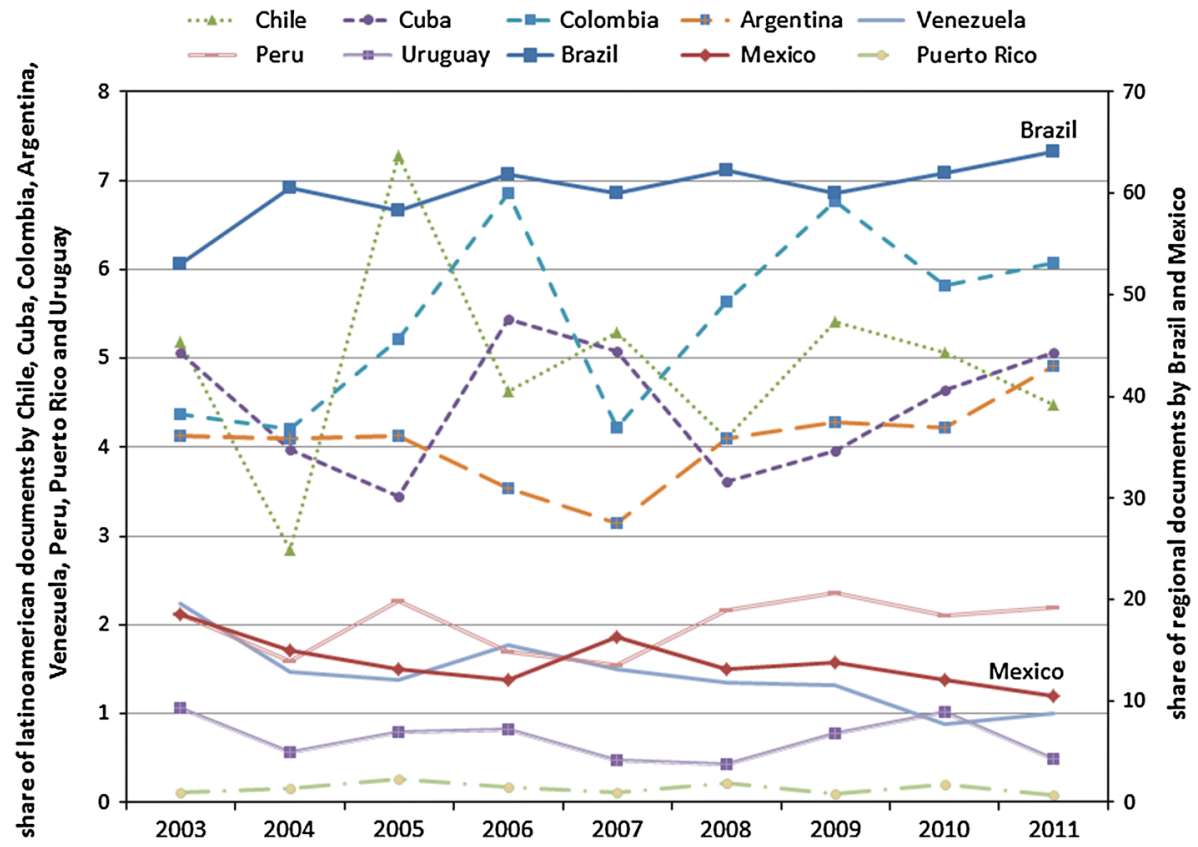

Fig. 1 Evolution of the relative share of the top 10 Latin American countries producing output in Public Health. Scopus 2003-2011. Source SCImago Institutions Rankings, from Scopus data elaborated by the authors

\section{Socio-economic indicators}

To contextualize the output of each country, we analyzed indicators of monetary investment and human resources, as well as the population of each country. The results show that Cuba and Puerto Rico had a greater volume of publication when the number of documents per one million inhabitants was standardized. They are followed by Brazil and Chile, with approximately five articles per one million inhabitants. Venezuela, Peru and Argentina were the countries with the smallest proportions. Although all the countries of study increased the average number of documents per one million inhabitants between the periods 2003-2007 and 2007-2011, the growth of Cuba during the second of these two periods is remarkable (Fig. 2).

In 2011, Cuba is the country seen to invest most heavily in health, in view of the GDP. Still, its percentage of investment per capita is low, especially in comparison with Brazil, the only country in the region who surpasses the recommended level of investment of $1 \%$ GNP. In sharp contrast, Peru and Venezuela (and to a lesser degree, Colombia and Mexico) directs much more limited resources towards Health (Table 3).

The highest figures for researchers per one million inhabitants correspond to Brazil and Argentina, followed by Puerto Rico and Uruguay. Venezuela shows the greatest percentage of researchers dedicated to Medical and Health Sciences, though the figures for Brazil and Chile are also high. Brazil appears to be the most determined as far as consistently investing in Health research is concerned. The figures for Peru, Colombia and Mexico vary more widely. Chile and Argentina stand out in terms of investment in Total Expenditure in health as well as percentage of GDP per capita. 


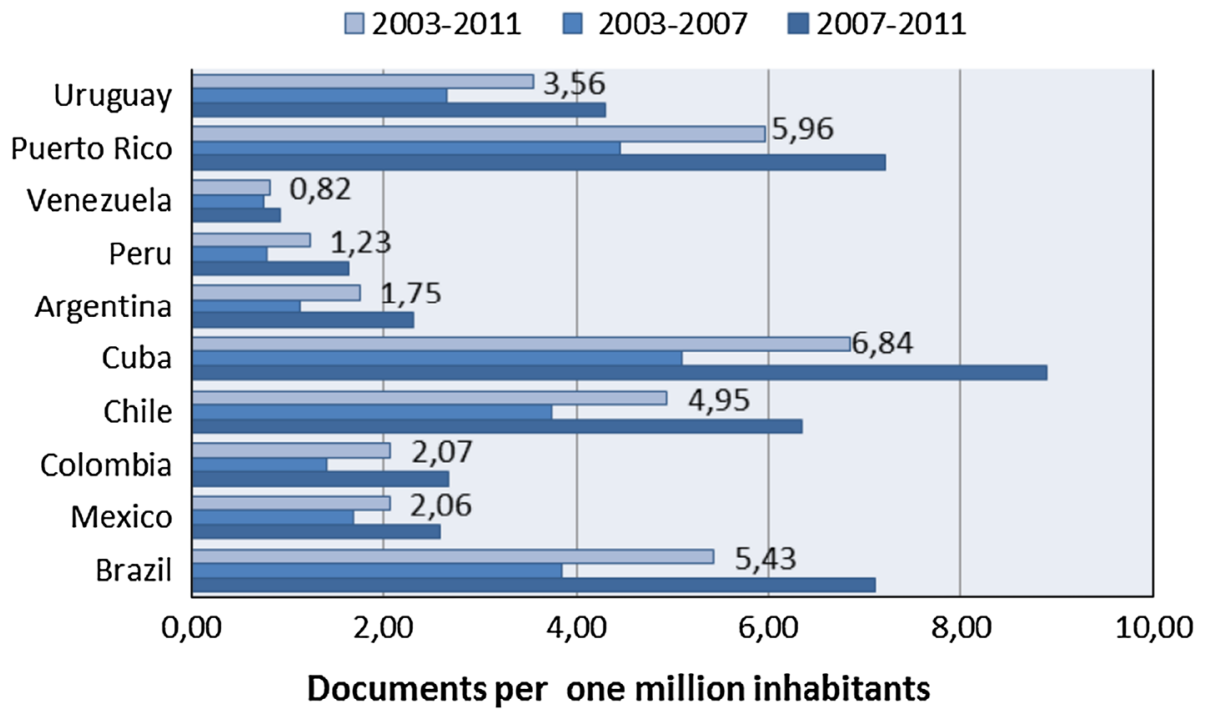

Fig. 2 Average number of documents in Public Health, adjusted to one million inhabitants, in the top 10 Latin American producers, according to Scopus. Period 2003-2011. Source SCImago Institutions Rankings, derived from Scopus data, and elaborated by the authors

\section{Patterns of publication in the scientific output in Public Health}

Analysis of the type of document helps identify the main channels of communication used to divulge results. The journal article is the main form of communication used in general. Over $80 \%$ of the output in each country relies on this documental format, with the exception of Mexico, Cuba and Chile-these three countries present the greatest proportions of reviews (respectively, 13,16 and $18 \%$ ). Conference papers are relatively infrequent in Latin America, the greatest contributions of this type coming from Puerto Rico, Mexico and Cuba, with about $7 \%$ of output. The category "others" (letters, notes, abstracts, press articles and surveys) is the one least used (Fig. 3).

The distribution of documents according to the language of publication reveals that all the countries of study attained a higher impact when they published in English (Table 4).

Brazil nearly doubled its citations received for English-language articles in comparison with the citations received for papers published in Spanish. Over half of Mexico's output is in English, and citations received for work in the English language are three times greater than for other languages. Colombia publishes $75 \%$ of its output in Spanish, but the citations received are 2.5 times those of the production when in English and over five times that in Portuguese. Chile receives four times more citations when it publishes in English, a major language for communication in their case. Cuba receives five times more citations for its English-language publications and almost six times as many when it publishes in Portuguese, yet it is the country with the greatest percentage of output in Spanish (87.45 \%). Argentina and Venezuela harvest roughly five times as many citations when publishing in English, and respectively nine and five times as in Peru, publication in English amounts to $85 \%$ of the total; and their documents in English or in Portuguese attract more than double the citations of those written in Spanish. Virtually all the output from Puerto Rico is in English. Finally, Uruguay also receives three times as many citations for the English-language papers. 


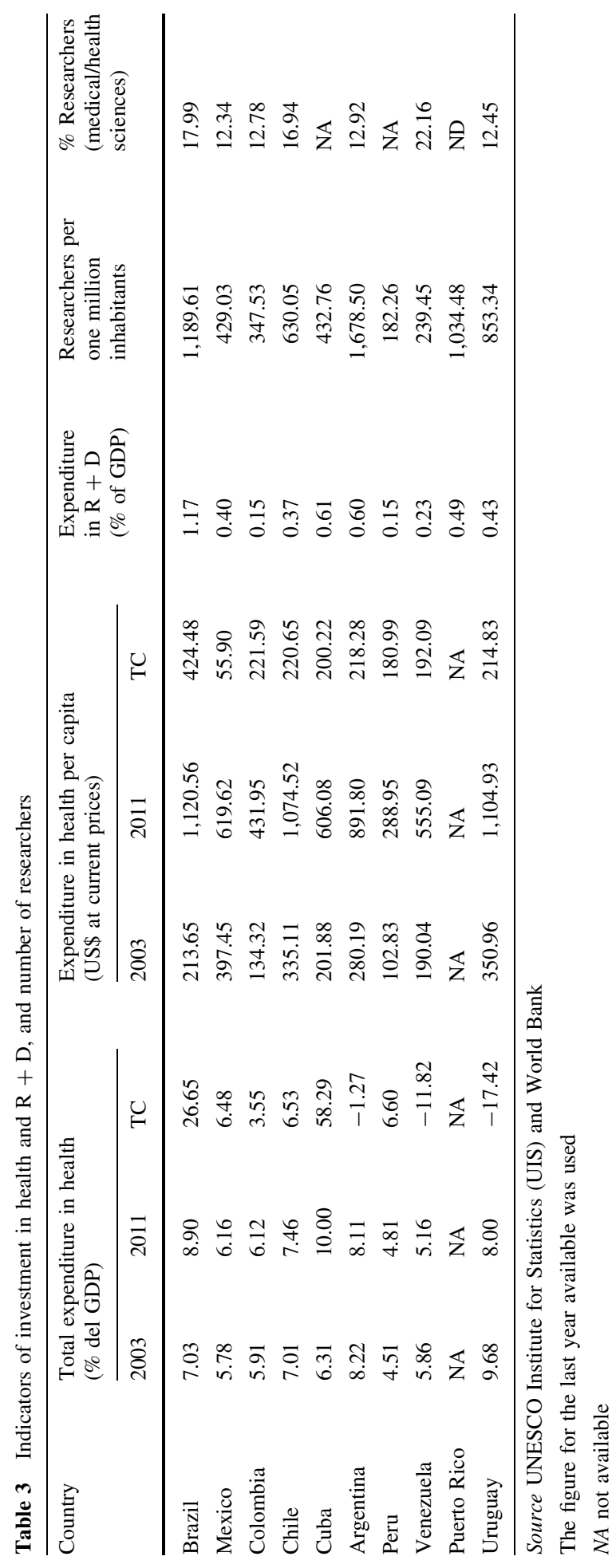




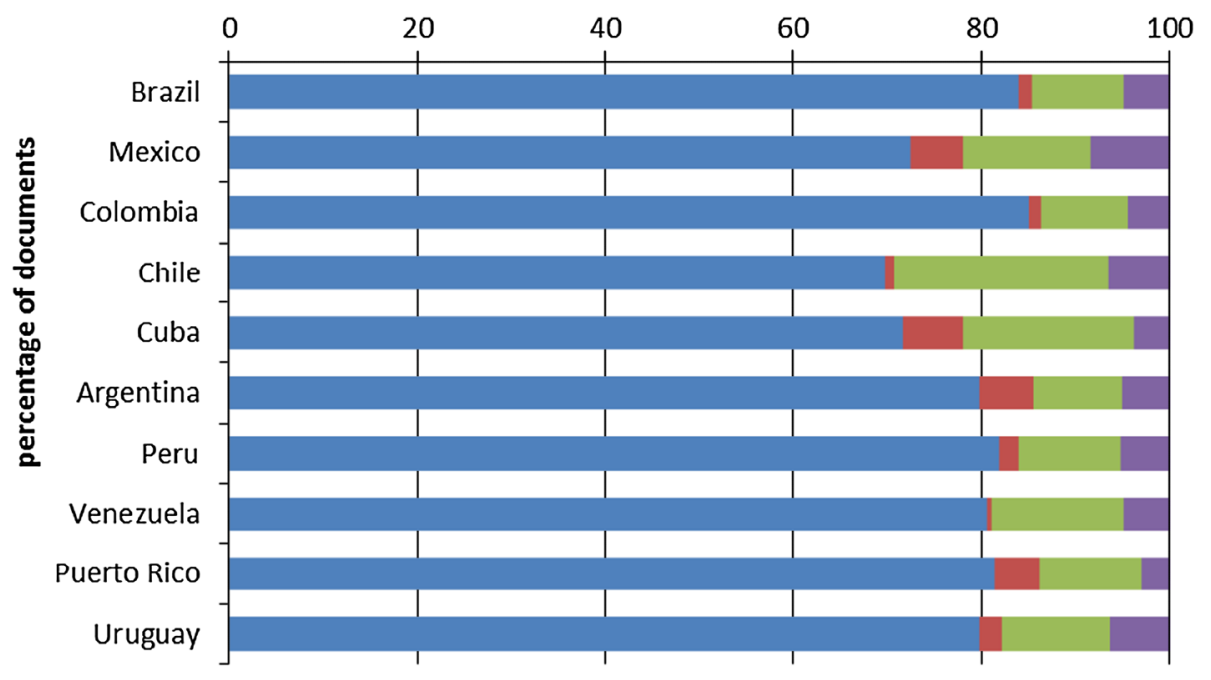

Article $\quad$ Conference Paper $\quad$ Review $\quad$ Others types

Fig. 3 Document type in the scientific output in Public Health for the top 10 Latin American producers. Scopus 2003-2011. Source SCImago Institutions Rankings derived from Scopus data, elaborated by the authors

Table 4 Percentage of documents and citations per document, by language of publication

\begin{tabular}{|c|c|c|c|c|c|c|c|c|c|c|c|}
\hline \multirow[t]{2}{*}{ Country } & \multicolumn{2}{|c|}{ English } & \multicolumn{2}{|c|}{ Spanish } & \multicolumn{2}{|c|}{ Portuguese } & \multicolumn{2}{|c|}{ Others } & \multirow{2}{*}{$\begin{array}{l}\text { Eng/ } \\
\mathrm{sp}\end{array}$} & \multirow{2}{*}{$\begin{array}{l}\text { Eng/ } \\
\text { por }\end{array}$} & \multirow[t]{2}{*}{ Overlap } \\
\hline & $\begin{array}{l}\% \\
\text { ndoc }\end{array}$ & cpd & $\begin{array}{l}\% \\
\text { ndoc }\end{array}$ & $\mathrm{cpd}$ & $\begin{array}{l}\% \\
\text { ndoc }\end{array}$ & cpd & $\begin{array}{l}\% \\
\text { ndoc }\end{array}$ & cpd & & & \\
\hline Brazil & 46.64 & 6.26 & 2.84 & 3.32 & 64.73 & 4.34 & 0.54 & 0.542 & 1.89 & 1.44 & 14.22 \\
\hline Mexico & 55.28 & 8.14 & 61.53 & 2.62 & 1.52 & 2.65 & 1.12 & 0.9 & 3.11 & 3.07 & 18.33 \\
\hline Colombia & 46.60 & 5.85 & 74.26 & 2.28 & 1.19 & 1.1 & 0.54 & 1.3 & 2.57 & 5.32 & 22.05 \\
\hline Chile & 40.70 & 8.74 & 67.87 & 1.99 & 0.54 & 4.25 & 0.24 & 1.25 & 4.39 & 2.06 & 9.10 \\
\hline Cuba & 30.74 & 3.74 & 87.45 & 0.81 & 0.87 & 0.67 & & & 4.62 & 5.58 & 19.05 \\
\hline Argentina & 67.94 & 8.31 & 33.17 & 1.76 & 1.91 & 0.92 & & & 4.72 & 9.03 & 3.03 \\
\hline Peru & 85.08 & 8.59 & 13.33 & 2.93 & 2.22 & 4.14 & & & 2.93 & 2.07 & 0.63 \\
\hline Venezuela & 64.71 & 8.98 & 37.25 & 2.42 & 4.90 & 2.5 & 1.59 & 1.35 & 3.71 & 3.59 & 6.86 \\
\hline $\begin{array}{r}\text { Puerto } \\
\text { Rico }\end{array}$ & 99.50 & 7.79 & 0.99 & 6 & & & & & 1.30 & & 0.50 \\
\hline Uruguay & 73.83 & 10.86 & 26.17 & 3.79 & 0.93 & 4 & & & 2.87 & 2.72 & 0.93 \\
\hline
\end{tabular}

Scopus 2003-2011

Source SCImago Institutions Rankings derived from Scopus data, elaborated by the authors

Most of the Latin American articles in Public Health are produced by the sector of Higher Education. This is not the case in Cuba and Mexico, however. There, research is predominantly carried out by the government, and within the health sector. In the private sector, output is almost non-existent. Within the sector "Other", the country accumulating most production is Peru, with over $12 \%$, followed by Colombia, Mexico and Venezuela (Table 5). 
As for the greater visibility of some countries with respect to others, in terms of normalized impact, we can see that in the sector of Higher Education, only Peru, Venezuela and Uruguay surpass the world mean impact; with respective figures of 11, 18 and $36 \%$. Argentina and Puerto Rico are near the world average, with a high proportion of documents. The rest of the countries are well below the world average, and Cuba has the least visibility of all. In the governmental sector, Cuba is the country with the greatest proportion, but citation is $85 \%$ below the world average. Argentina, with over $31 \%$ of its production in Public Health originating in governmental institutions, is $30 \%$ above the world average. Mexico relies more heavily on the Health Sector, harvesting results of more impact there than through centers of Higher Education. Brazil, with a quarter of its output stemming from hospitals and other health centers, obtains the best visibility when compared with all the other sectors analyzed. The same is true of Colombia and Cuba, although their visibility is far from the world mean. A look at "other" sectors shows that despite little output, impact is greater in the case of Brazil and Chile.

Finally, the countries with the least production are the ones reaching the highest rates of impact, above all in Higher Education and the Health Sector. The exception to this rule would be Puerto Rico. Table 6 gives the main indicators of total output per country.

Peru is an interesting case. Its international participation is nearly $80 \%$, and its cited production is $25 \%$ higher than the world average. In Uruguay, $71 \%$ of output is carried out by international institutions, and it receives $42 \%$ more citations than the world average. In Puerto Rico, the total production is $34 \%$ below the world mean, despite the fact that $57 \%$ of output is done in collaboration with other countries. This country only achieves good visibility for $8.9 \%$ of output in the Health sector, with $61 \%$ more citations than the world mean. In terms of international collaboration, Brazil is weakest (13\% of its participation involving foreign institutions), followed by Cuba (19.34\% collaborative efforts). These two countries share a high level of leadership, 94 and $89 \%$, respectively. That is, they had high volumes of output whose first (corresponding) authors were national citizens. Overall, Brazil presents a better balance between leadership and excellence than Cuba, as it had a better value in the excellence with leadership indicator, and there is less of a difference between the two indicators.

Focusing on the main producers, Argentina stands out as the country with the best results in normalized impact, with output slightly over the world mean for citation. Similar results are obtained by Venezuela, but with a contribution of publications per se that is just one-third that of Argentina. Cuba is the least visible country; its yield is 74 points below the world average. This is due to the low percentage of documents published in the better journals (Q1), the lesser proportion of articles of excellence, and the low rate of collaboration. Chile, Colombia and Brazil are also among the countries with the least visibility in terms of normalized impact, the low percentage of documents in Q1, and few articles among the $10 \%$ highly cited at the worldwide level (excellence).

Peru, Puerto Rico and Uruguay were the countries publishing more articles in the first quartile, and in the chapter of excellence. In view of the fact that the reference point for excellence is $10 \%$, only two countries (Peru and Uruguay) are situated above the world mean, with respective values of 11.11 and $17.76 \%$. However, the leadership of these countries is low, and the excellence with leadership is likewise low; that is, the authors responsible for the highly cited documents do not pertain to that nationality. In the case of Uruguay, the set of highly cited documents owes exclusively to associations with foreign institutions, as there is no leadership in any document. Still, in the case of Peru, $2.87 \%$ of its highly cited output is led by Peruvian authors. This is an example of a genuine capacity for 
Table 5 Distribution of the number of Public Health documents and Normalized Impact, by institutional sectors for the top 10 Latin American producers

\begin{tabular}{|c|c|c|c|c|c|c|c|c|c|c|}
\hline \multirow[t]{2}{*}{ Country } & \multicolumn{2}{|c|}{ Higher education } & \multicolumn{2}{|c|}{ Government } & \multicolumn{2}{|c|}{ Health sector } & \multicolumn{2}{|l|}{ Private } & \multicolumn{2}{|l|}{ Other } \\
\hline & $\%$ Ndoc & NI & $\%$ Ndoc & NI & $\%$ Ndoc & NI & $\%$ Ndoc & NI & $\%$ Ndoc & NI \\
\hline Brazil & 88.58 & 0.65 & 11.25 & 0.78 & 25.92 & 0.82 & 0 & 0.78 & 0.47 & 1.01 \\
\hline Mexico & 43.74 & 0.82 & 7.87 & 0.95 & 69.16 & 0.84 & 0.02 & 0.67 & 4.94 & 0.82 \\
\hline Colombia & 85.10 & 0.51 & 0.95 & 0.44 & 25.27 & 0.77 & 0.01 & 0.34 & 6.08 & 0.77 \\
\hline Chile & 78.18 & 0.54 & 0.40 & 0.22 & 40.70 & 0.32 & 0 & 0 & 4.15 & 1 \\
\hline Cuba & 20.78 & 0.2 & 41.27 & 0.15 & 49.49 & 0.39 & 0 & 0 & 0.29 & 0 \\
\hline Argentina & 62.36 & 0.96 & 31.42 & 1.3 & 19.94 & 0.86 & 0.01 & 1.14 & 3.51 & 1.03 \\
\hline Peru & 60.00 & 1.11 & 7.62 & 1.73 & 43.49 & 1.46 & 0.01 & 0.94 & 12.38 & 1.06 \\
\hline Venezuela & 80.88 & 1.18 & 21.08 & 0.56 & 30.88 & 1.09 & 0.01 & 0.37 & 4.41 & 0.64 \\
\hline Puerto Rico & 87.62 & 0.83 & 1.49 & 0 & 8.91 & 1.61 & 0 & 0 & 0 & 0 \\
\hline Uruguay & 59.81 & 1.36 & 2.80 & 0.66 & 34.58 & 1.64 & 0 & 0 & 2.80 & 2.04 \\
\hline
\end{tabular}

Scopus 2003-2011

Source SCImago Institutions Rankings derived from Scopus data, elaborated by the authors

Table 6 Main bibliometrics indicators of the top 10 Latin American producers in Public Health in Scopus

\begin{tabular}{lrllllll}
\hline Countries & Ndoc & NI & $\%$ Q1 & \% Exc & \% Lead & \% EwL & $\%$ Col \\
\hline Brazil & 9,356 & 0.66 & 20.33 & 4.68 & 94.03 & 3.45 & 13.03 \\
Mexico & 2,046 & 0.81 & 20.09 & 6.6 & 79.18 & 2.74 & 37.83 \\
Colombia & 839 & 0.59 & 15.02 & 4.29 & 77.59 & 0.95 & 34.92 \\
Chile & 747 & 0.57 & 17.94 & 4.95 & 82.6 & 1.2 & 26.91 \\
Cuba & 693 & 0.26 & 7.22 & 2.16 & 88.89 & 0.43 & 19.34 \\
Argentina & 627 & 1.02 & 30.14 & 7.34 & 70.02 & 2.87 & 46.73 \\
Peru & 315 & 1.25 & 46.67 & 11.11 & 40.32 & 2.54 & 79.68 \\
Venezuela & 204 & 1.02 & 29.41 & 9.31 & 69.61 & 2.45 & 40.2 \\
Puerto Rico & 202 & 0.86 & 46.04 & 7.43 & 57.92 & 0.5 & 56.93 \\
Uruguay & 107 & 1.42 & 39.25 & 17.76 & 42.99 & 0 & 71.03 \\
\hline
\end{tabular}

Period 2003-2011

Source SCImago Institutions Rankings derived from Scopus data, elaborated by the authors

initiating and directing research efforts. Brazil is responsible for the leadership of practically $73 \%$ of its output of excellence. Mexico does so with $41 \%$ and Argentina nearly $40 \%$.

These figures reflect certain strengths in the field and a healthy trend of taking the initiative when it comes to research in Public Health. These countries are capable of extending the quality of leadership in research to other international colleagues, especially in the case of Brazil, whose level of international participation is so low.

According to the Spearman's Rank correlation coefficient ("Annex", Table 8) for the bibliometric indicators of total output, as the volume of scientific production increases, so does leadership, whereas excellence decreases. The percentage of documents in Q1 shows a positive correlation with excellence, and a negative correlation with leadership. The percentage of leadership, in turn, decreases with greater excellence, greater Q1, greater collaboration and higher normalized impact. It is very noteworthy that the percentage of excellence with 
leadership does not correlate with any of the indicators. International collaboration is strongly associated in a positive sense with percentages of Q1, excellence and NI; in the negative sense, it is associated with the volume of output and leadership. Normalized impact showed a strong positive correlation with documents in Q1, excellence and international collaboration; and a moderately negative association with the number of documents and the percentage of leadership. Greater international participation resulted in better visibility.

The question now is: Why does increased scientific leadership not imply increased excellence and publication in the best journals, with higher impact? One reason may be the low level of international collaboration, and another the high proportion of publication in non-English language journals, both these factors conditioning visibility. In some cases, we corroborated that output of excellence with leadership was largely due to leadership output. Hence, certain countries manage to make substantial advances in knowledge through genuine research leadership.

\section{Health indicators}

In order to determine to what extent research has influenced the state of health of populations, health indicators are given and analyzed below.

Cuba and Chile are the countries that have the best health indicators, especially given the low infant mortality rate (under age 1) seen for Cuba. Uruguay may also be considered to provide good health results. At the other extreme, Colombia, Brazil and Peru have deficient health statistics according to these basic indicators (Table 7).

As a "synthetic" indicator covering the overall health situation of a country's population, we took the values of the INIQUIS indicator, found in a study aiming to identify the situation of inequality in terms of health among the countries of Latin America and the Caribbean, for the period 2005-2010. The INIQUIS indicator embraces a set of socioeconomic and health indicators elaborated by international organisms, that are held to be proximal and contextual with respect to health. The lower the value of the indicator, the more favorable the state of health. The results of our study clearly show that the vast majority of countries are situated in the range 0.2-0.4. This index places Cuba, Argentina, Uruguay and Chile in a more favorable situation, whereas Venezuela would be one of the poorest countries in terms of the health of its citizens (Table 7).

Figure 4 displays the relationship of the INIQUIS figures with respect to the volume of output (size of the spheres) and the visibility of output, as measured by the standardized impact. Cuba is an outlier with high levels of health and low scientific impact. In contrast, Venezuela takes on a value near the world mean in impact, but shows a low level of health among the population. Not too far away appear Colombia and Peru. The scientific output of Peru, however, attains a much higher level of impact than Columbia. Uruguay and Argentina are found in a favorable situation health-wise, and also achieved a level of impact above the world average. Our results show that the INIQUIS figures do not correlate with indicators for output or visibility ("Annex", Table 8).

\section{Discussion}

Latin America is undergoing huge moves forward in the political, economic and cultural integration of its geographic member states (Mendoza-Parra et al. 2009; UNESCO 2010; Barreto et al. 2012). The countries of the region share problems of a socioeconomic nature, 
Table 7 Basic health indicators by country, 2011

\begin{tabular}{|c|c|c|c|c|c|}
\hline Country & $\begin{array}{l}\text { Life expectancy } \\
\text { at birth }\end{array}$ & $\begin{array}{l}\text { Infant } \\
\text { mortality }^{\mathrm{b}}\end{array}$ & $\begin{array}{l}\text { Mortality, children } \\
\text { under age } 5^{\mathrm{b}}\end{array}$ & $\begin{array}{l}\text { Maternal } \\
\text { mortality }^{\mathrm{c}}\end{array}$ & $\begin{array}{l}\text { INIQUIS } \\
2005-2010\end{array}$ \\
\hline Brazil & 74 & 14 & 16 & 56 & 0.3425 \\
\hline Mexico & 75 & 13 & 16 & 50 & 0.3418 \\
\hline Colombia & 78 & 15 & 18 & 92 & 0.3872 \\
\hline Chile & 79 & 8 & 9 & 25 & 0.2880 \\
\hline Cuba & 78 & 5 & 6 & 73 & 0.0323 \\
\hline Argentina & 76 & 13 & 14 & 77 & 0.2480 \\
\hline Peru & 77 & 14 & 18 & 67 & 0.3999 \\
\hline Venezuela & 75 & 13 & 15 & 92 & 0.5407 \\
\hline Uruguay & 76 & 9 & 10 & 29 & 0.2671 \\
\hline
\end{tabular}

Source Global Health Observatory, World Health Organization. INIQUIS: Cardona et al. (2013)

Note Data not available for Puerto Rico

${ }^{\text {a }}$ In years

${ }^{\mathrm{b}}$ Per 1,000 live births

c Per 100,000 live births,Data from 2010

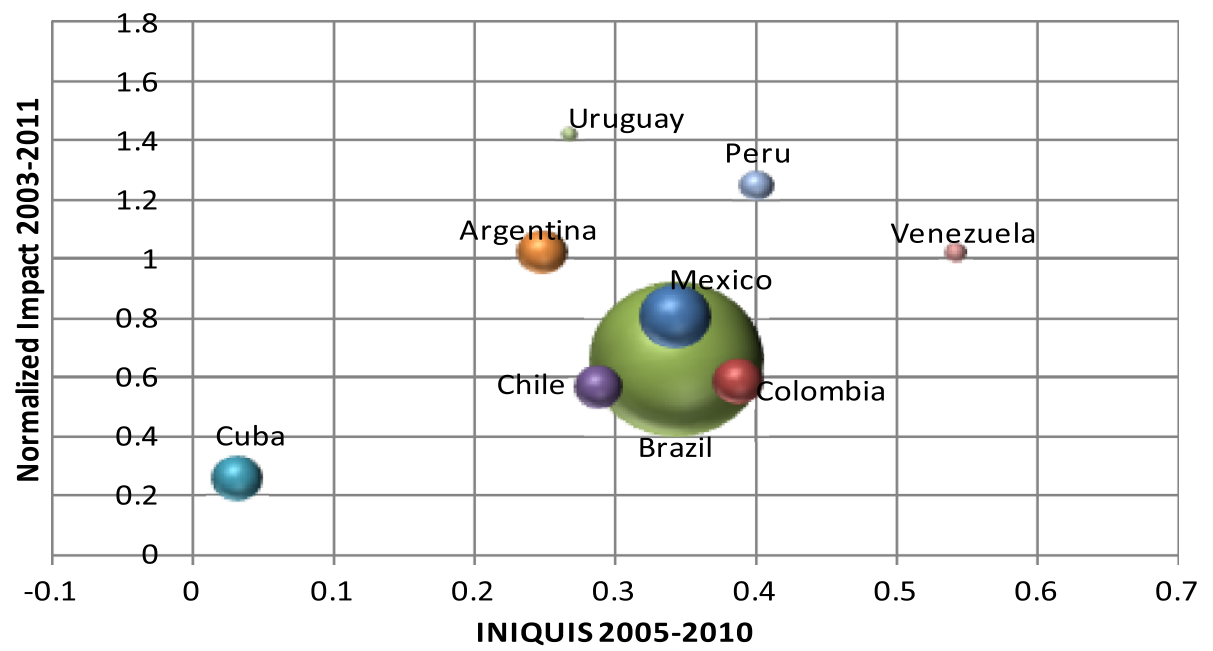

Fig. 4 Normalized impact, INIQUIS (2005-2010) and volume of output (size of the sphere, 2003-2011). Source From INIQUIS, Cardona et al. (2013)

and also have common ground within the context of research. For instance, there is scarce funding, and financing is moreover inconsistent over time. Overall, we might underline the absence of research policies, the incapacity to establish research priorities, the insufficiency of qualified human resources, and the poor infrastructure for carrying out research (Santa and Herrero-Solana 2010). In other words, research in Public Health is hindered by the same discrepancies that exist on the broad geographic level. We identified high, medium, low and very low producers of Public Health research (high: Brazil; medium: Mexico, Colombia, Cuba, Chile and Argentina; low: Peru, Venezuela, Puerto Rico and 
Uruguay; very low: the rest of the Latin American countries. Just two countries of Latin America, namely Brazil and Mexico, generate over three-quarters of the total output in this domain of knowledge.

Brazil has the best-balanced research profile in Latin America. It has consolidated a vast, reputable system of science and technology, and its scientific community has grown considerably in the past two decades, as demonstrated by studies involving different databases (Macías-Chapula 2005a, b; Huamaní et al. 2012). The low visibility of the articles published by Brazilian institutions in Public Health appears to be influenced by publication in national or regional journals, implying the Portuguese language in most cases. These findings are in consonance with the results of previous work, documenting high levels of self-citation (Glänzel et al. 2006) and high levels of publication in national journals (Molina-Molina and Moya-Anegón 2013). Brazil produces over half of the output in Public Health in Latin America on the whole. Whereas its growth is continuous, its level of cooperation is low. Brazil is a strong research leader, managing to publish articles that are highly cited when foreign institutions participate in their research initiatives. The state of health of the grass-roots population, meanwhile, is deficient in comparison with the other countries dealt with here.

The situation of Mexico is also interesting. It has a well integrated health research system, which in recent years has slowed down a bit in growth and visibility. It is now $20 \%$ below the world average. Two other noteworthy characteristics of Mexican scientific output are its high degree of leadership and the low level of collaboration. In the end, however, it accumulates one of the best proportions of output of excellence with leadership.

Colombia stands out due to the rising growth trend in its scientific activity and results. Its presence in journals of the first quartile, and in the $10 \%$ most cited journals, is low. It is high in leadership, while both collaboration and excellence with leadership are low. The health indicators for its population are not among the best regionally. According to recent studies, Colombia has undergone unprecedented growth in the Scopus database: 59 titles of Colombian journals were recently incorporated, representing $10 \%$ of all Latin American journals in Scopus (Molina-Molina and Moya-Anegón 2013).

The scientific output of Argentina is low if we compare it with the vast population of the country. Nevertheless, we detected a high level of growth, high impact, excellence and leadership in the scientific production of this country when it works in the realm of Public Health. A similarly high level of leadership and international collaboration has been reported by the Clinical Medicine in Argentina (Huamaní et al. 2012). The nationwide investment in health research in general is quite high in comparison with other Latin American countries, and the inhabitants of Argentina have a good state of health overall. We might therefore suggest that there could be equilibrium between research efforts and generalized results in Public Health.

Peru, Puerto Rico and Uruguay do not have the same levels of health, but they may be grouped together by virtue of their similar patterns of scientific communication. These three countries have a low volume of published documents, yet their communication is largely in English, involving high levels of international collaboration. They yield the scientific output of highest impact and excellence. Publication for these countries within journals of the top quartile is high, as is output in the $10 \%$ most cited works. Yet despite high levels of collaboration, a lack of leadership is evident. Their researchers are less autonomous and they depend on cooperative efforts that prove to be immensely fruitful. Puerto Rico and Uruguay, on the other hand, show the highest figures for number of researchers. 
Chile and Cuba can proudly display the best health indicators, according to our analysis. Their output in Public Health has little impact, and the record of just $10 \%$ of works highly cited and/or in journals of the first quartile is hardly remarkable. The growth of Cuba has deaccelerated in recent years, though their per capita production (weighted by one million inhabitants) is still high. Cuban scientific authors lead research work that hardly attains visibility, however, and does not attract collaboration. This, together with reticent output in English, conditions their visibility in comparison with the other countries of the region. Venezuela - despite its low level of Public Health, low investment in research, low numbers of researchers and scarce scientific output—attains high visibility. Therefore, we might affirm that the results of scientific activity do not reflect equivalent levels of development or effectiveness of the health system, and research does not readily filter down into the Public Health practice.

Chile is one of the countries with the greatest investment in health.... but not in research. Of the funds destined to 768 research projects in health for the period 2002-2006, only $10 \%$ pertained to the category of Public Health, as opposed to 66 and $24 \%$ for biomedical and clinical research, respectively. These figures serve as a warning to interpret data with some caution, as investment in research is one thing, while the distribution of funds over different research lines may be another matter (Paraje 2010).

Certainly, Latin American countries are dealing with two systems where a high quality publication is needed. The first system, aim to knowledge transfer at regional/world scale, but also promotes academic visibility at international channels. The goal of the second one is to fortify publication with local/national/regional scope in order to facilitate knowledge transfer generates from research into tangible practice, for example, through the soft systems approach (Macías-Chapula 2012). In the first one, English language is required, as well as collaboration and the accomplishment of the international standards of publications; meanwhile in the second, native/local language is probably more desirable.

The main patterns concerning publication, type of document and language of publication are significant for visibility. The most usual vehicle of scientific communication is the article, but the review is another important type of document. It may have more potential for high visibility, as these documents cover the situation and tendencies of a broader span-in space and over time. Moreover, these documents are often prepared and published on request (by an editor), making them very important when impact is calculated. In view of the results seen for countries such as Chile, Cuba and Mexico, the review is an important form of output. Nonetheless, this supposed visibility does not necessarily translate into impact, Q1 publications or excellence-probably because of their diffusion in the Spanish language. The language bias, both in journals and in citation patterns, clearly favors English: non-English language publication implies substantially lower impact.

Previous studies (Egghe et al. 1999; Egghe and Rousseau 2000; Van Leeuwen et al. 2001; Chinchilla-Rodríguez et al. 2014) have demonstrated that the language bias plays an important role in the evaluation of research systems. Other studies using different databases find a reasonably large proportion of output in Portuguese in Latin America, given the high productivity of Brazil, and assert that it is a habitual pattern of communication for Latin American countries to publish in the mother tongue (Macías-Chapula 2005a, b; MacíasChapula et al. 2005). This tendency has also been described for Europe. After English, German is the most common language in Public Health output, followed by French, Spanish and Portuguese (Clarke et al. 2007). In our study, scarce publication in English seems to affect the visibility of the countries, especially in the cases of Cuba, Chile and Brazil. A strategy that might improve visibility quite decisively would be to strive to publish in English in both national and international journals, and urge editorial committees to invite the international community of scientists to participate in English-language communications. 
We might also direct attention to a greater international participation giving rise to enhanced visibility. The countries with lowest productivity have a higher tendency to collaborate than the countries with highest leadership. Advanced scientific development and leadership may mean greater autonomy and a lesser need to collaborate (Huamaní et al. 2012). Leading countries like Brazil and Argentina act as proxies in the network of intra-regional collaboration. In contrast, smaller countries like Peru, Puerto Rico and Uruguay have to collaborate with countries scientifically more advanced to compensate for their size and expertise.

Although it is not a pattern common to the main regional producers, previous studies of Latin America point to international openness as a direction to be recommended in all fields (Ríos-Gómez and Herrero-Solana 2005) and concretely those related to Medicine, Clinical Medicine and Epidemiology (Chinchilla-Rodríguez et al. 2012; Huamaní et al. 2012; Barreto et al. 2012). According to Barreto, Latin America has two important advantages in relation to other regions: a similar cultural identity and a common language for most of the population. In the case of PROSUL, the South American Program was launched to support regional cooperation, encouraging South-to-South collaboration in science-intensive fields. Even though co-authorship between Latin American countries is increasing, it remains insufficient compared with the collaboration of non-Latin American countries (Chinchilla-Rodríguez et al. 2012; Huamaní et al. 2012). Thus, the region faces a fourfold challenge: to strengthen communication between researchers and policy makers to deal with commons health problems, specially, global health matter; to establish research partnerships within and outside the region; to boost internationally collaborative master's and doctoral programs; and to support and develop formal forums to promote collaboration between Latin American research institutions and universities (Barreto et al. 2012).

The correlation between the indicators studied here reveals that quality and quantity do not go hand in hand. According to our analysis, greater scientific output implies higher leadership, less visibility, less excellence and less collaboration. One factor heavily influencing the visibility of research results would be the language of publication. A high percentage of non-English publications stands as a linguistic constraint in reaching the widest possible audience, despite being indexed in international databases. The leadership indicator proved to be the one best defining the capacities of scientific output, tied to excellence with leadership; but high leadership was found to be correlated with low levels of collaboration. The low rate of collaboration with other countries also seems unfinished business, especially considering the leadership that can be a good engine for internationalization of research conducted in the region. Also, the lack of correlation between the INIQUIS and the bibliometric indicators signals a very relevant possibility: research findings do not influence the reality of the Public Health situation at ground level as much as policy-makers might wish to believe. This condition of the second system alert that there is a dire need to fortify the transfer of knowledge generated from research into tangible practice. Research efforts in Public Health ought to more specifically address the need for programs that aspire to improve the population's level of health and quality of life in the short-to-mid term (Clarke et al. 2007; Huamaní et al. 2012; Cardona et al. 2013).

\section{Conclusions}

Latin American is increasing its presence in the international scientific community, but there are considerable differences among the countries. We identified high, medium and low producers of Public Health research. Inequity in the state of health in Latin American 
countries is reflected by a high concentration of scientific publications in countries with structured systems of health research, as Brazil and Mexico demonstrate. Peru, Puerto Rico and Uruguay, with more limited scientific output, have high degrees of collaboration, and consequently greater visibility for their scientific output. The situation is different in Cuba and Chile, where intermediate volumes of output coexist with great achievements in health per se, not reflected in the results of Public Health research.

No single country stands out as having an ideal profile in the three dimensions analyzed here: publications, investment, and health. Still, there is a relative balance in Brazil, Uruguay and Argentina, despite different levels of scientific output in Public Health. Further research about social, economics and politics indicators is needed in order to get a better picture of the research capacity of these countries.

The relatively low level of publication in most countries mirrors a widespread insufficiency of scientific activity in this vast world region. Given the low levels of health in Latin America documented by various organizations, there should be a peaked interest on the part of governmental agents in augmenting investment in research directed toward the most blatant health problems of the region, and promote international activity via collaborations with other institutions and countries. In the near future, rigorous research would almost necessarily spill over into the terrains of publication and scientometrics. And eventually, fruitful research efforts translate as greater equity and better health indicators.

There is much to be done in this area, and even more to be approached through research initiatives. The results presented here shed light on some of the publication patterns and their implications for international visibility. Yet they also underline the need to design more sophisticated methods to evaluate scientific results, to determine how effectively research responds to populations in need of Public Health care. The scientometric approach can prove increasingly useful as additional tools are devised. Methods that can be used to analyze the macro and the micro levels of Public Health research and results will stir up a more refined discussion of research policy and the actions needed to improve quality and equity in the realm of Public Health, and the application of scientific knowledge to human well-being.

\section{Annex}

See Table 8.

Table 8 Coefficient of correlation of Spearman range among indicators

\begin{tabular}{lcccccccc}
\hline Indicators & Ndoc & $\%$ Q1 & $\%$ Exc & $\%$ Lead & $\%$ EwL & $\%$ Col & NI & INIQUIS \\
\hline Ndoc & 1.00 & -0.661 & $-0.770^{* *}$ & $0.818^{* *}$ & 0.564 & $-0.782^{* *}$ & $-0.675^{*}$ & 0.0 \\
$\%$ Q1 & -0.661 & 1.00 & $0.879^{* *}$ & $-0.818^{* *}$ & 0.103 & $0.855^{* *}$ & 0.875 & 0.267 \\
$\%$ Exc & $-0.770^{* *}$ & $0.879^{* *}$ & 1.00 & $-0.879^{* *}$ & -0.079 & $0.891^{* *}$ & $0.942^{* *}$ & 0.250 \\
$\%$ Lead & $0.818^{* *}$ & $-0.818^{* *}$ & $0.879^{* *}$ & 1.00 & 0.273 & $-0.976^{* *}$ & $-0.851^{* *}$ & -0.350 \\
$\%$ EwL & 0.564 & 0.103 & -0.079 & 0.273 & 1.00 & -0.188 & 0.061 & 0.250 \\
$\%$ Col & $-0.782^{* *}$ & $0.855^{* *}$ & $0.891^{* *}$ & $-0.976^{* *}$ & -0.188 & 1.00 & $0.875^{* *}$ & 0.200 \\
NI & $-0.675^{*}$ & $0.875^{* *}$ & $0.942^{* *}$ & $-0.851^{* *}$ & 0.061 & $0.875^{* *}$ & 1.00 & 0.276 \\
INIQUIS & 0.0 & 0.267 & 0.250 & -0.350 & 0.250 & 0.200 & 0.276 & 1.00 \\
\hline
\end{tabular}

Scopus 2003-2011

Source SCImago Journal and Country Rank, from Scopus data elaborated by the authors

* Bilateral correlation is significant at the level 0.05 ;** Bilateral correlation is significant at the level 0.01 


\section{References}

Alger, J., Becerra-Posada, F., Kennedy, A., Martinelli, E., Cuervo, L. G., et al. (2009). Sistemas nacionales de investigación para la salud en América Latina: Una revisión de 14 países. Revista Panamericana de Salud Publica, 26(5), 447-457.

Barreto, S., Miranda, J., Figueroa, J., Schmidt, M., Muñoz, S., Kuri-Morales, P., et al. (2012). Epidemiology in Latin America and the Caribbean: Current situation and challenges. International Journal of Epidemiology, 41, 557-571.

Becerra-Posada, F. (2009). El rol de COHRED en el desarrollo de los sistemas de investigación para la salud en América Latina. http://www.cohred.org/sites/default/files/Seminario_INSP_COHRED_ 250309_1.pdf. Accessed 5 June 2010.

Bornmann, L., Moya-Anegón, F., \& Leydesdorff, L. (2012). The new excellence indicator in the World Report of the SCImago Institutions Rankings 2011. Journal of Informetrics, 6(2), 333-335.

Cardona, D., Acosta, L., \& Bertone, C. (2013). Inequidades en salud entre países de Latinoamérica y el Caribe (2005-2010). Gaceta Sanitaria, 27(4), 292-297.

Chinchilla-Rodríguez, Z., Arencibia-Jorge, R., Corera-Álvarez, E., \& Moya-Anegón, F. (2014). Some patterns of publications in Cuban scientific domain in Scopus: current situation and challenges. Scientometric,

Chinchilla-Rodríguez, Z., Benavent-Pérez, M., Miguel, S., \& Moya-Anegón, F. (2012). International collaboration in medical research in Latin America and the Caribbean (2003-2007). Journal of the American Society for Information Science and Technology, 63(11), 2223-2238.

Clarke, A., Gatineau, M., Grimaud, O., Royer-Devaux, S., Wyn-Roberts, N., Bis, I., et al. (2007). A bibliometric overview of Public Health research in Europe. European Journal of Public Health, 17(1), 43-49.

COHRED. (2006). Supporting health research system development in Latin America. Results of Latin America Regional Think Tank, August 2006.

COHRED. (2013). Advances in the development of NHRS in the region. http://www.cohred.org/supportingcountries-to-build-systems-that-focus-health-research-on-achieving-equity-and-national-development/ national-health-research-systems-in-latin-america/advances-in-the-development-of-nhrs-in-the-region. Accessed 26 Sept 2013.

Egghe, L., \& Rousseau, R. (2000). Partial orders and measures for language preferences. Journal of the American Society for Information Science, 51(12), 1123-1130.

Egghe, I., Rousseau, R., \& Yitzhaki, M. (1999). The "own-language preference": Measures of relative language self-citation. Scientometrics, 45(2), 217-232.

Gilson, L. (1999). Implementing and evaluating health reform processes: Lessons from the literature. Informing and Reforming, 10(11), 2-3.

Glänzel, W., Leta, J., \& Thijs, B. (2006). Science in Brazil. Part 1: A macro-level comparative study. Scientometrics, 67(1), 67-86.

Global Health Observatory (2013). http://apps.who.int/gho/data/view.main. Accessed 9 July 2013.

González-Pereira, B., Guerrero-Bote, V., \& Moya-Anegón, F. (2010). A new approach to the metric of journals' scientific prestige: The SJR indicator. Journal of Informetrics, 4(3), 379-391.

Huamaní, C., González, G., Curioso, W., \& Pacheco-Romero, J. (2012). Redes de colaboración y producción científica sudamericana en medicina clínica, ISI CurrentContents 2000-2009. Revista Médica de Chile, 140, 466-475.

Jeremić, V., Jovanoviæ-Milenkoviæ, M., Radojièiæ, Z., \& Martiæ, M. (2013). Excellence with leadership: The crown indicator of SCImago Institutions Rankings Iber Report. El Profesional de la Información, 22(5), 474-480.

Macías-Chapula, C. A. (2005a). Hacia un modelo de comunicación en salud pública en América Latina y el Caribe. Revista Panamericana de Salud Pública, 18(6), 427-438.

Macías-Chapula, C. A. (2005b). Health system reforms in Latin American and the Caribbean. Scientometrics, 53(3), 407-427.

Macías-Chapula, C. A. (2010). Influence of local and regional publications in the production of Public Health research papers in Latin America. Scientometrics, 84, 703-716.

Macías-Chapula, C. A. (2012). Diseño de un modelo conceptual sobre la transferencia de resultados de investigación en salud pública en Honduras. Salud Publica de México, 54(6), 624-631.

Macías-Chapula, C. A., Rodea-Castro, I. P., Mendoza-Guerrero, J. A., \& Gutiérrez-Carrasco, A. (2005). Visualization of knowledge production on Public Health research. In Proceedings of ISSI 2005.

Magaña-Valladares, L., Nigenda-López, G., Nidia Sosa-Delgado, M., \& Ruiz-Larios, J. A. (2009). Public Health Workforce in Latin America and the Caribbean: Assessment of education and labor in 17 countries. Salud Pública de México, 51(1), 62-75. 
Maloney, A. (2009). Latin America faces hurdles in health research. Lancet, 374, 1053-1054.

Mays, G., Halverson, P., \& Scutchfield, F. (2003). Behind the curve? What we know and need to learn from public health systems research. Journal of Public Health Management Practice, 93(3), 179-182.

Mendoza-Parra, S., Paravic-Kljin, T., Muñoz-Muñoz, A., Barriga, O., \& Jiménez-Contreras, E. (2009). Visibility of Latin American nursing research. Journal of Nursing Scholarship, 41(1), 54-63.

Molina-Molina, S., \& Moya-Anegón, F. (2013). Política nacional y visibilidad internacional. El caso colombiano. El Profesional de la Información, 22(6), 529-535.

Moya-Anegón, F., Chinchilla-Rodríguez, Z., Vargas-Quesada, B., Corera-Álvarez, E., González-Molina, A., \& Muñoz-Fernández, F. J. (2007). Coverage analysis of Scopus: A journal metric approach. Scientometrics, 73, 53-78.

Moya-Anegón, F., Guerrero-Bote, V., Bortmann, L., \& Moed, H. (2013). The research guarantors of scientific papers and the output counting: A promising new approach. Scientometrics, 97, 421-434.

Lansang M.A. \& Dennis R. (2004). Building capacity in health research in thedeveloping world. Bulletin World Health Organization, 82(10), 764-770.

Organización Panamericana de la Salud. (2007). Capacidades en salud pública en América Latina y el Caribe: evaluación y fortalecimiento. Washington, DC: OPS.

Organización Panamericana de la Salud. (2008). La Aportación Regional al Foro Ministerial Mundial sobre Investigaciones para la Salud (CD48/17). 48. Consejo Directivo 60. Sesión del Comité Regional. Washington, DC: OPS.

Paraje, G. (2010). El financiamiento público de la investigación en salud en Chile. Revista Médica de Chile, $138(1), 36-43$.

Rehn, C., \& Kronman, U. (2008). Bibliometric handbook for KarolinskaInstitutet. KarolinskaInstitutet University Library. Version 1.05.

Ríos-Gómez, C., \& Herrero-Solana, V. (2005). La producción científica latinoamericana y la ciencia mundial: Una revisión bibibliográfica (1989-2003). Revista Interamericana de Bibliotecología, 28(I), 43-61.

Santa, S., \& Herrero-Solana, V. (2010). Producción científica de América Latina y el Caribe: Una aproximación a través de los datos Scopus (1996-2007). Revista Interamericana de Bibliotecología, 33(2), $379-400$.

SCImago. (2007). SIR—SCImago Institutions Rankings. http://www.scimagoir.com. Accessed 11 June 2013.

SCOPUS. (2013). http://www.scopus.com. Accessed 11 June 2013.

UNESCO. (2010). UNESCO Science Report 10. Paris: UNESCO publishing. http://unesdoc.unesco.org/ images/0018/001899/189958e.pdf. Accessed 9 July 2013.

Van Leeuwen, T., Moed, H., Tijssen, R., Visser, M., \& Van Raan, A. (2001). Language biases in the coverage of the Science Citation Index and its consequences for international comparisons of national research performance. Scientometrics, 51(1), 335-346.

Work Bank Data. (2010). http://data.worldbank.org. Accessed 27 Jan 2013.

Zacca-González, G., Chinchilla-Rodríguez, Z., Vargas-Quesada, B. \& Moya-Anegón, F (2014) Regional distribution of scientific output in Public Health. Latin America in the international context. Scopus 1996-2011. BMC Public Health (in press). 